\title{
Long-term results of percutaneous balloon aortic valvuloplasty in children with aortic stenosis: a single-center experience
}

\author{
Krzysztof Godlewski ${ }^{1}$ Bożena Werner² \\ 1 Department of Pediatric Cardiology, University Clinic Centre of the Medical University of Warsaw, Warsaw, Poland \\ 2 Department of Pediatric Cardiology and General Pediatrics, Medical University of Warsaw, Warsaw, Poland
}

\section{KEY WORDS}

aortic stenosis, balloon aortic valvuloplasty, children
Correspondence to: Prof. Boziena Werner, MD, PhD, Department of Pediatric Cardiology and General Pediatrics, Medical University of Warsaw, ul. Żwirki i Wigury 63A, 02-091 Warszawa, Poland, phone +48223179588 , email: bozena.werner@wum.edu.pl Received: November 11, 2019. Revision accepted: March 22, 2020.

Published online: March 23, 2020. Kardiol Pol. 2020; 78 (6): 559-566 doi:10.33963/KP.15245 Copyright by the Author(s), 2020

\begin{abstract}
BACKGROUND Percutaneous balloon aortic valvuloplasty (BAV) is an effective method of treatment for aortic stenosis in children.

AIMS This study aimed to assess the long-term results of BAV in various age groups in the pediatric population. METHODS This retrospective study included 68 patients (newborns, infants, and children older than 1 year). We analyzed their demographic data and measurements performed with the use of cardiac catheterization, angiography, and echocardiography at 3 time points: before, directly after, and at late follow-up after BAV, including the invasive aortic valve peak-to-peak systolic pressure gradient $\left(\mathrm{PG}_{\text {peak }}\right)$, maximum systolic pressure gradient $\left(\mathrm{PG}_{\max }\right.$ ) by Doppler echocardiography, and the severity of aortic regurgitation (AR). Long-term follow-up data were available for 57 patients.

RESULTS The BAV procedure led to a significant reduction in the $P_{\text {peak }}$ values. Late follow-up revealed a progression of AR. Aortic regurgitation of grade 2 or higher directly after BAV was the strongest risk factor for severe AR at late follow-up. After 5, 10, and 18 years after BAV, surgical treatment was not required in 90\%, $77 \%$, and $59.5 \%$ of patients, respectively. Severe AR and a residual PG less than $35 \mathrm{~mm} \mathrm{Hg}$ at late follow-up were stronger risk factors for aortic valve surgery than moderate AR and PG higher than or equal to $35 \mathrm{~mm} \mathrm{Hg}$. CONCLUSIONS Balloon aortic valvuloplasty is an effective method of treatment for aortic stenosis in children, which delays the need for surgery. The progression of AR occurs at late follow-up. A greater reduction in $\mathrm{PG}_{\max }$ is a risk factor for at least moderate $A R$ directly after $B A V$, which results in the progression of $A R$ at late follow-up.
\end{abstract}

INTRODUCTION Congenital aortic stenosis (AS) is the most common form of left ventricular outflow tract obstruction (accounting for $2 \%$ to $6 \%$ of all congenital heart defects). ${ }^{1}$ Percutaneous balloon valvuloplasty (BAV) is an established method of treatment for AS with proven efficacy in children. ${ }^{2,3}$ However, at late follow-up after BAV, worsening of the patient's hemodynamic status is observed. It is therefore justified to examine factors that affect the need for and the timing of surgical treatment at late follow-up.

In this article, we present the results of 20-year single-center experience with percutaneous treatment of AS in children.
The aim of our study was to assess the long-term results of BAV in the treatment of AS in terms of reducing the systolic pressure gradient (PG) across the aortic valve, the presence of postprocedural aortic regurgitation (AR), and factors affecting the development of severe AR and the need for valve surgery at late follow-up.

METHODS We conducted a retrospective analysis of 68 patients divided into 3 age groups (newborns, infants, and children older than 1 year) who had undergone BAV for AS in our tertiary referral cardiology center. Long-term follow-up 


\section{WHAT'S NEW?}

The optimal management of patients with congenital aortic valve stenosis is a challenge for modern pediatric cardiology. Percutaneous balloon aortic valvuloplasty (BAV) is widely used as a primary treatment in children with aortic stenosis. Many reports show the immediate outcome of percutaneous BAV in children with aortic stenosis. Our study is one of the few works showing the long-term results of this procedure. It indicated that, in order to obtain the longest possible period for aortic valve surgery, we should not try to reduce the pressure gradient (PG) below $35 \mathrm{~mm} \mathrm{Hg}$ during the procedure. We found out that severe aortic regurgitation (AR) and a residual PG less than $35 \mathrm{~mm} \mathrm{Hg}$ at late follow-up were stronger risk factors for cardiac surgery than moderate $A R$ and $a P G$ higher than $35 \mathrm{~mm} \mathrm{Hg}$. Moderate regurgitation occurring directly after BAV appeared to be the strongest risk factor for the development of severe AR at late follow-up.

data were available for 57 patients. Clinical data were obtained for the period from establishing the patient's eligibility for BAV to the endpoint defined as the date of the most recent cardiovascular examination, aortic valve surgery, death, or the patient turning 18 years of age.

We analyzed patients' demographic data, measurements obtained during cardiac catheterization and angiography, and parameters assessed by echocardiography at 3 time points: before BAV, directly after BAV, and at late follow-up after $\mathrm{BAV}$. The invasive assessment of the aortic valve peak-to-peak systolic pressure gradient $\left(\mathrm{PG}_{\text {peak }}\right)$ was performed before and just after BAV. Echocardiography was used to evaluate the morphology of the aortic valve, the diameter of the aortic annulus, the ratio of the balloon diameter to the aortic annulus diameter (the balloon-to-annulus ratio), left ventricular size and function by ejection fraction, the maximum LV-Ao systolic pressure gradient $\left(\mathrm{PG}_{\max }\right)$, and the severity of AR (on a 4-point grading scale).

Statistical analysis The following statistical methods were used for data analysis: the $t$ test, the Mann-Whitney test, the Shapiro-Wilk test, the nonparametric $\mathrm{X}^{2}$ test, and the Kruskal-Wallis test in the analysis of variance (ANOVA). The hypotheses were tested at a significance level of 0.05 . The Kaplan-Meier curves were used for survival times for various endpoints, and the log-rank test was used to compare them. Multivariate logistic regression analysis was conducted in order to determine risk factors for the need of surgery. Odds ratios with the respective $95 \%$ CIs were provided for each predictor. Statistical calculations were performed using the Statistica software, version 13.1 (Tibco, Palo Alto, California, United States).

The study was approved by the local ethics committee.

TABLE 1 Characteristics of the study population: invasive hemodynamic and echocardiographic data obtained before and after balloon aortic valvuloplasty

\begin{tabular}{|c|c|c|c|c|c|}
\hline \multicolumn{2}{|l|}{ Parameter } & Overall $(n=68)$ & Newborns $(n=44)$ & Infants $(n=17)$ & Children at age $>1$ y $(n=7)$ \\
\hline \multicolumn{2}{|c|}{ Age, median (range) } & $17.5(1-5479) d$ & $8.4(1-30) d$ & $75(30-165) d$ & $13(1-15)$ y \\
\hline \multicolumn{2}{|c|}{ Weight, kg, median (range) } & $3.7(2.4-90)$ & $3.5(2.4-4.7)$ & $4.6(2.9-6.8)$ & $54.5(22-90)$ \\
\hline \multicolumn{2}{|l|}{ Male sex, n (\%) } & $44(64.7)$ & $32(72.7)$ & $9(52.9)$ & $3(42.8)$ \\
\hline \multirow{3}{*}{$\begin{array}{l}\mathrm{PG}_{\text {peak }} \text { ' }, \mathrm{mm} \mathrm{Hg} \text {, } \\
\text { mean (SD); range }\end{array}$} & Before BAV & $67.6(19.1) ; 20-122$ & 64.6 (14.9); 20-102 & $69.6(24.7) ; 30-120$ & 81.8 (23.3); 56-122 \\
\hline & Immediately after BAV & $24(10.9) ; 5-55$ & $22.8(9.7) ; 5-55$ & $21.6(9.9) ; 9-40$ & $37(12.8) ; 22-55$ \\
\hline & $P$ value & $<0.001$ & $<0.001$ & $<0.001$ & 0.017 \\
\hline \multicolumn{2}{|c|}{$\begin{array}{l}\mathrm{PG}_{\text {peak }} \text { reduction } \geq 50 \% \text { of the pre-BAV } \\
\text { value, } \%\end{array}$} & 80.9 & 84.1 & 82.4 & 57.14 \\
\hline \multirow{3}{*}{$\begin{array}{l}\mathrm{PG}_{\max }{ }^{\mathrm{b}}, \mathrm{mm} \mathrm{Hg} \text {, } \\
\text { mean (SD); range }\end{array}$} & Before BAV & $70.86(20.9) ; 5-120$ & $67.95(20.4) ; 5-100$ & 70.24 (20.8); 25-100 & 90.71 (15.9); 70-120 \\
\hline & Immediately after BAV & $29.5(11) ; 10-76$ & $28.63(11.4) ; 10-76$ & $28.24(7.6) ; 18-43$ & 38.1 (13.2); 15-52 \\
\hline & $P$ value & $<0.001$ & $<0.001$ & $<0.001$ & 0.023 \\
\hline \multirow[t]{4}{*}{$A R, n(\%)$} & AR grade $\leq 1$ before BAV & $20(29.4)$ & $9(20.45)$ & $7(41.2)$ & $4(57.1)$ \\
\hline & $\begin{array}{l}\text { AR grade } \geq 3 \text { immediately } \\
\text { after BAV }\end{array}$ & $1(1.5)$ & $1(2.3)$ & 0 & 0 \\
\hline & AR grade $\geq 3$ at follow-up & $19(33.4)$ & $13(38.2)$ & $5(31.2)$ & $1(14.3)$ \\
\hline & $P$ value & $<0.01$ & - & - & - \\
\hline
\end{tabular}


RESULTS Patients who were considered eligible for BAV included those with severe or critical AS and those with moderate AS who also exhibited signs of left ventricular hypertrophy, cardiac arrhythmias, or signs of low cardiac output.

The BAV procedures were carried out under general anesthesia with endotracheal intubation, via the right common carotid artery or femoral artery access. The procedure was monitored by fluoroscopy and transthoracic echocardiography, using the parasternal left ventricular long-axis and subcostal views. The balloon diameter was sized for the aortic valve diameter determined on angiography with an up to 1:1 ratio.

Detailed patient characteristics are shown in TABLE1. A total of $71 \mathrm{BAV}$ procedures were carried out in the overall population of 68 patients (with $3 \mathrm{pa}-$ tients having undergone 2 procedures in the given time interval). A total of 16 patients (23.5\%; newborns and infants) were also diagnosed with other cardiovascular defects, such as atrial septal defect, ventricular septal defect, coarctation of the aorta, mitral stenosis, pulmonary stenosis, and congenital anomalies in other organ systems.

The immediate results of the procedures and the data obtained during cardiac catheterization and echocardiography are summarized in TABLE1. Following the BAV procedure, a significant decrease in the $P G_{\text {peak }}$ values was observed in the overall population and in the individual age groups. In 62 patients (91.2\%), $\mathrm{PG}_{\text {peak }}$ did not exceed $50 \mathrm{~mm} \mathrm{Hg}$ immediately after the procedure, whereas it persisted at a level above $50 \mathrm{~mm} \mathrm{Hg}$ in the remaining 6 patients (8.8\%). A decrease in $P G_{\text {peak }}$ of $50 \%$ or greater compared with the baseline value was achieved in $80.9 \%$ of all treated patients, including $81.1 \%, 82.4 \%$, and $57.14 \%$ of newborns, infants, and children older than 1 year, respectively. The percentage reduction in $P G_{\text {peak }}$ did not differ between the individual age groups.

No grade $4 \mathrm{AR}$ was observed after the procedure in any patient. Aortic regurgitation on postprocedural echocardiography was revealed in 65

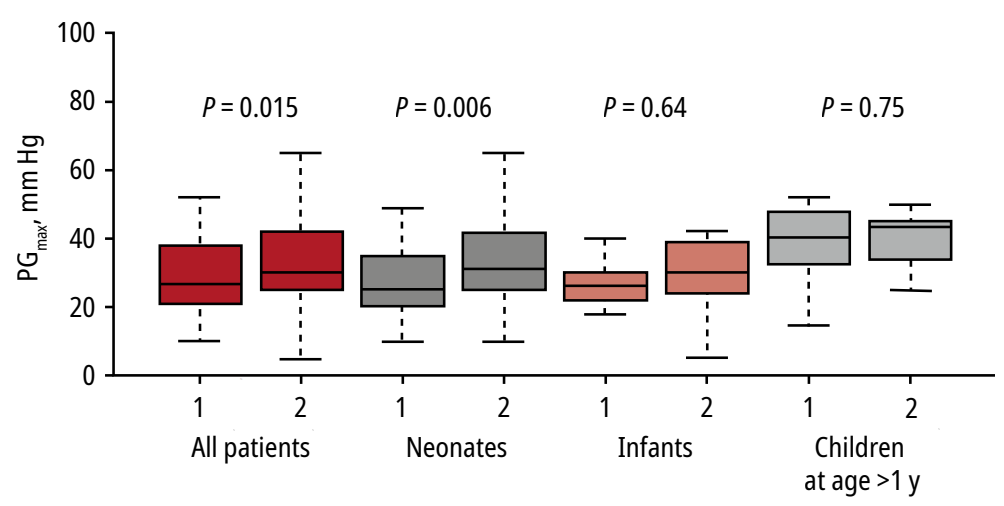

FIGURE 1 Comparison of instantaneous peak systolic Doppler gradient measurements immediately after balloon aortic valvuloplasty (1) and at long-term follow-up (2) in children Abbreviations: $\mathrm{PG}_{\mathrm{max}}$ instantaneous peak systolic gradient patients (94.1\%), including $42(61.8 \%)$ with grade $1 \mathrm{AR}, 22$ (32.3\%) with grade $2 \mathrm{AR}$, and 1 patient (1.5\%) with grade 3 AR. Three patients underwent another BAV procedure within 2 to 42 days following the initial intervention, with restenosis being the reason in 2 patients and an inadequate result of the initial procedure in 1 patient.

Procedural complications were observed in 14 patients (20.6\%), $60 \%$ of which were related to vessel cannulation, and the remaining $40 \%$ to arrhythmias and damage to cardiac structures. There were no intraprocedural deaths. A total of 11 patients died within 15 hours to 7 months after BAV, including 4 persons who died after cardiac surgery for coexisting cardiac defects or after surgical aortic valve commissurotomy preceded by unsuccessful balloon valvuloplasty (endocardial fibroelastosis). The median (range) postprocedural survival was 49 (19122) days. Multivariate retrograde logistic regression analysis showed that risk factors for mortality prior to BAV included: lower $z$ score for the left ventricular internal end-diastolic diameter $(P=0.02$; odds ratio [OR], 0.14); lower $z$ value for the aortic valve diameter $(P=0.01$; OR, 0.18), impaired left ventricular (ejection fraction) systolic function ( $P=0.04 ; \mathrm{OR}, 184)$, and mitral valve regurgitation of at least grade 2 ( $P=0.04$; OR, 174).

In the remaining 57 patients, the late follow-up was continued until 1 of the endpoints was achieved. The mean (SD) duration of follow-up in the overall study population was 95.2 (74.4) months (median, 82 months).

The mean (SD) $P_{\text {max }}$ at late follow-up (measured during the most recent cardiovascular examination) was 34.2 (14.6) $\mathrm{mm} \mathrm{Hg}$ in the overall study population and was significantly $(P=0.015)$ higher than $\mathrm{PG}_{\max }$ directly after the procedure. The mean (SD) $P G_{\max }$ values at late follow-up in the individual age groups were also higher than those measured directly after the procedure: 35 (15.7) $\mathrm{mm} \mathrm{Hg}, 30.2$ (12.8) $\mathrm{mm} \mathrm{Hg}$, and 39.3 (10.1) $\mathrm{mm} \mathrm{Hg}$ in newborns, infants, and children older than 1 year, respectively. The difference was significant in the group of newborns $(P=0.006)$ yet not in the remaining 2 groups (infants and children older than 1 year; $P=0.64$ and $P=0.75$, respectively) (FIGURE1). At late follow-up, no significant differences in $P G_{\max }$ between the individual age groups were observed $(P=0.11)$. Left ventricular systolic function assessed by conventional echocardiography (ejection fraction) was normal in all patients at long-term follow-up.

We analyzed factors that affected $P G_{\max }$ at late follow-up by assessing the parameters listed in TABLE2 for 2 subgroups of patients: those with a PG $G_{\max }$ less than $35 \mathrm{~mm} \mathrm{Hg}$ and those with a $P G_{\max }$ of $35 \mathrm{~mm} \mathrm{Hg}$ or higher. The proportion of patients with severe AR occurring directly after the procedure in the first subgroup was significantly $(P=0.04)$ higher than that in the second 
TABLE 2 Factors affecting the instantaneous peak systolic Doppler gradient value at long-term follow-up after balloon aortic valvuloplasty

\begin{tabular}{|c|c|c|c|c|}
\hline Parameter & & $\begin{array}{l}\text { Patients with } \\
\mathrm{PG}_{\max } \geq 35 \mathrm{~mm} \mathrm{Hg}(\mathrm{n}=26)\end{array}$ & $\begin{array}{l}\text { Patients with } \\
\mathrm{PG}_{\max }<35 \mathrm{~mm} \mathrm{Hg}(\mathrm{n}=31)\end{array}$ & $P$ value \\
\hline \multirow[t]{3}{*}{ Age group, \% } & Newborns & 61.6 & 58.1 & \multirow[t]{3}{*}{0.19} \\
\hline & Infants & 19.2 & 35.5 & \\
\hline & $\begin{array}{l}\text { Children } \\
\text { at age }>1 \text { y }\end{array}$ & 19.2 & 6.4 & \\
\hline$P G_{\text {max }}$ before $B A V, m m ~ H g$, mean (SD); range & & 77.84 (17.4); 42-120 & $71.3(18.2) ; 25-120$ & 0.21 \\
\hline \multirow[t]{2}{*}{ AR immediately after BAV, $\%$} & Grade $>2$ & 23.1 & 48.4 & \multirow[t]{2}{*}{0.04} \\
\hline & Grade $\leq 2$ & 76.9 & 51.6 & \\
\hline Aortic annulus $z$ score at BAV, median (range) & & $-0.14(-1.79$ to 1.34$)$ & $-0.28(-4.79$ to 2.75$)$ & 0.89 \\
\hline \multirow[t]{2}{*}{ Aortic valve morphology, $\%$} & Two-leaflet & 57.7 & 77.4 & \multirow[t]{2}{*}{0.11} \\
\hline & Other & 42.3 & 22.6 & \\
\hline \multirow[t]{2}{*}{ LVEF before BAV, \% } & $<64 \%$ & 23.1 & 38.7 & \multirow[t]{2}{*}{0.2} \\
\hline & $\geq 64 \%$ & 76.9 & 61.3 & \\
\hline $\mathrm{B} / \mathrm{A}$ ratio ${ }^{\mathrm{a}}$, mean $(\mathrm{SD})$; range & & $0.92(0.08) ; 0.66-1.01$ & $0.93(0.05) ; 0.85-1$ & 0.58 \\
\hline \multirow[t]{2}{*}{ Reduction in the pre-BAV PG ${ }_{\max }$ value, \% } & $>50 \%$ & 69.2 & 74.2 & \multirow[t]{2}{*}{0.67} \\
\hline & $\leq 50 \%$ & 30.8 & 25.8 & \\
\hline \multirow[t]{2}{*}{ AR at long-term follow-up, $\%$} & Grade $\geq 2$ & 19.2 & 45.2 & \multirow[t]{2}{*}{0.03} \\
\hline & Grade $<2$ & 80.8 & 54.8 & \\
\hline
\end{tabular}

a The ratio of diameters measured on angiography

Abbreviations: B/A, balloon-to-aortic valve annulus; LVEF, left ventricular ejection fraction; others, see TABLE1

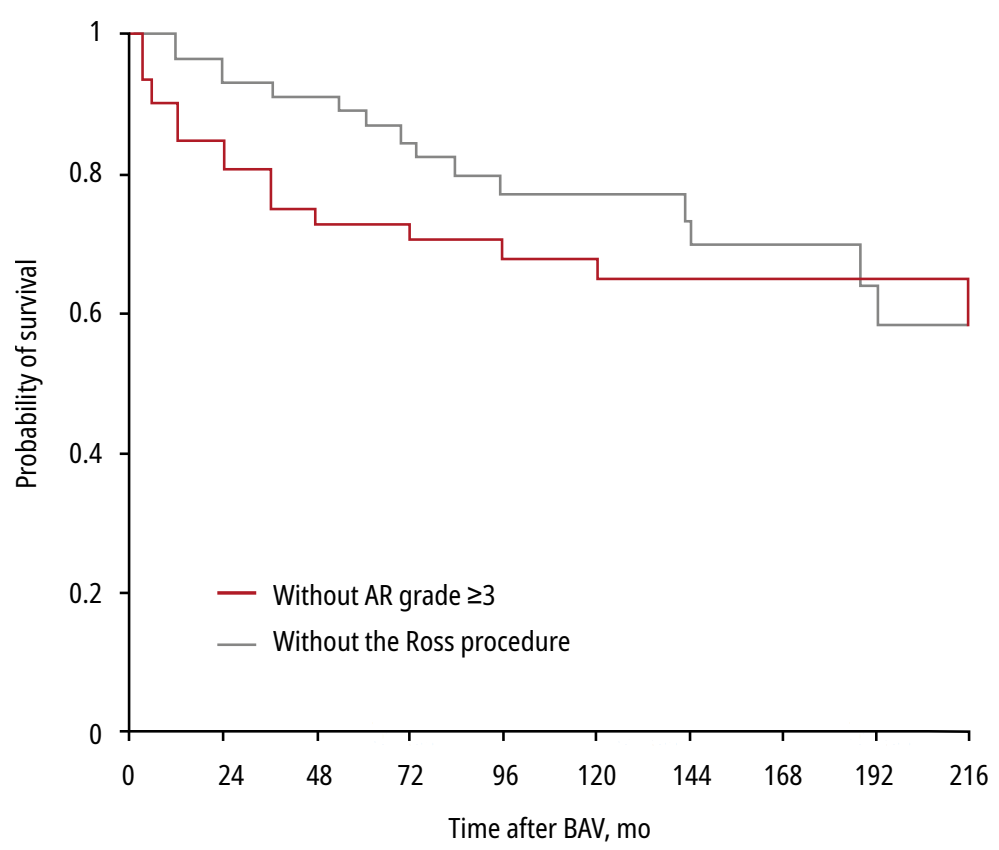

FIGURE 2 Kaplan-Meier curves showing the probability of survival without significant (grade $\geq 3$ ) aortic regurgitation (AR) and without surgical reintervention after balloon aortic valvuloplasty (BAV) in the entire study group one. We also showed a significantly $(P=0.03)$ higher proportion of patients with AR of grade lower than 2 in the most recent assessment in the subgroup with a $P G_{\max }$ equal to or higher than $35 \mathrm{~mm} \mathrm{Hg}$. The comparative analysis of other parameters listed in TABLE 2 showed no significant differences between the subgroups.

At late follow-up, AR (grade 1, 2, 3, or 4) was observed in $98.2 \%$ of the patients, with $33.4 \%$ having severe AR. The proportion of patients with severe AR during the examination preceding the achievement of an endpoint differed significantly from the proportion of those with severe AR directly after the procedure $(P<0.01)$. Severe AR was observed in $25 \%, 34 \%$, and $37 \%$ of the patients 5,10 , and 18 years after BAV, respectively (FIGURE2).

We analyzed the factors affecting the development of severe AR during the long-term followup for 2 categories of patients: 19 patients with severe AR and 38 with AR of grade 2 or higher. The parameters and their categorization are provided in TABLE3. We found significant differences between the groups regarding the proportion of patients with AR occurring directly after BAV (categories: grade $\geq 2 \mathrm{AR}$ and grade $<2 \mathrm{AR})(P=0.003)$, the proportion of patients with a residual $P G_{\max }$ directly after BAV (categories: $\mathrm{PG}_{\max } \geq 35 \mathrm{~mm} \mathrm{Hg}$ and $\left.P G_{\text {peak }}<35 \mathrm{~mm} \mathrm{Hg}\right)(P=0.04)$, and the mean balloon-to-annulus ratio $(P=0.03)$. 
TABLE 3 Factors affecting the significant grade of aortic regurgitation at long-term follow-up after balloon aortic valvuloplasty

\begin{tabular}{|c|c|c|c|c|}
\hline \multicolumn{2}{|l|}{ Parameter } & \multirow{2}{*}{$\begin{array}{l}\text { Patients with AR of grade } \leq 2(n=38) \\
55.3\end{array}$} & \multirow{2}{*}{$\begin{array}{l}\text { Patients with AR of grade }>2(n=19) \\
68.4\end{array}$} & \multirow{2}{*}{$\begin{array}{l}P \text { value } \\
0.43\end{array}$} \\
\hline Age group, $\%$ & Newborns & & & \\
\hline & Infants & 28.9 & 26.3 & \\
\hline & $\begin{array}{l}\text { Children } \\
\text { at age }>1 \text { y }\end{array}$ & 15.8 & 5.3 & \\
\hline $\mathrm{PG}_{\max }$ before $\mathrm{BAV}, \mathrm{mm} \mathrm{Hg}$, mean (SD) & & $70.75(22.4)$ & $71.42(17.22)$ & 0.87 \\
\hline \multirow[t]{2}{*}{$\mathrm{PG}_{\max }$ immediately after BAV, \% } & $\geq 35 \mathrm{~mm} \mathrm{Hg}$ & 34.2 & 10.5 & \multirow[t]{2}{*}{0.043} \\
\hline & $<35 \mathrm{~mm} \mathrm{Hg}$ & 65.8 & 89.5 & \\
\hline \multicolumn{2}{|l|}{ Aortic annulus $z$ score at BAV, median (range) } & $-0.28(-1.22$ to 0.78$)$ & $-0.16(-0.9$ to 0.64$)$ & 0.49 \\
\hline \multirow[t]{2}{*}{ Aortic valve morphology, $\%$} & Two-leaflet & 63.2 & 78.9 & \multirow[t]{2}{*}{0.22} \\
\hline & Other & 36.8 & 21.1 & \\
\hline \multirow[t]{2}{*}{ LVEF before BAV, \% } & $<64 \%$ & 23.7 & 42.1 & \multirow[t]{2}{*}{0.22} \\
\hline & $\geq 64 \%$ & 76.3 & 57.9 & \\
\hline $\mathrm{B} / \mathrm{A}$ ratio, mean $(\mathrm{SD})$; range & & $0.92(0.06) ; 0.66-1$ & $0.95(0.04) ; 0.88-1.01$ & 0.03 \\
\hline \multirow[t]{2}{*}{ Reduction in the pre-BAV PG ${ }_{\max }$ value, $\%$} & $>50 \%$ & 65.8 & 84.2 & \multirow[t]{2}{*}{0.14} \\
\hline & $\leq 50 \%$ & 34.2 & 1.8 & \\
\hline \multirow[t]{2}{*}{ AR immediately after BAV, \% } & Grade $\geq 2$ & 23.7 & 63.2 & \multirow[t]{2}{*}{0.003} \\
\hline & Grade $<2$ & 76.3 & 36.8 & \\
\hline
\end{tabular}

Abbreviations: IQR, interquartile range; see TABLES 1 and 2

Surgical treatment of the aortic valve (the Ross procedure or the Ross-Konno procedure) at various time points after BAV was required in 15 patients, including 3 in whom the operation was needed because of aortic valve damage secondary to infectious endocarditis. In all patients, AR was an indication for surgery. There were no complex heart defects in the operated group. The mean time from BAV to surgical treatment was 6.6 years (range, $0.5-16$ years) in the overall population, 6.8 years in the group of newborns, and 7.3 years in the group of infants. In 1 patient who underwent BAV at the age below 1 year surgery was performed after 30 months. Of the 15 patients who subsequently underwent surgery, 9 had undergone BAV as newborns, 5 as infants, and 1 at the age below 1 year. Surgical treatment of the aortic valve was not required in $90 \%, 77 \%$, and $59.5 \%$ of the patients after 5 , 10 , and 18 years after BAV respectively (FIGURE 2 ). Considering the division into age groups (newborns and the remaining patients), aortic valve surgery 18 years after BAV was not required in $40 \%$ and $64 \%$ of the study patients, respectively. The difference between these 2 groups did not reach significance $(P=0.62$ in the log-rank test) (FIGURE 3A).

In order to identify risk factors affecting the need for cardiac surgery, we performed the univariate analysis of the parameters listed in TABLE 4 and compared the Kaplan-Meier curves for $P G_{\text {max }}$ and $A R$ in the subgroup of patients who did not require surgery. We showed significant differences between the subgroups (patients operated on versus those not requiring surgery) in the proportion of patients with severe AR directly after the procedure $(P=0.005)$ and in the proportion of severe AR at late follow-up $(P<0.001)$ (TABLE 4, FiguRE 3B and 3C). The groups of patients operated on and those who did not require surgery were compared for $\mathrm{PG}_{\max }$ at late follow-up in 2 categories: PG $G_{\max }$ less than $35 \mathrm{~mm} \mathrm{Hg}$ and PGmax equal to or higher than $35 \mathrm{~mm} \mathrm{Hg}$ (FIGURE 3D). The proportion of patients with a $\mathrm{PG}_{\max }$ less than $35 \mathrm{~mm} \mathrm{Hg}$ significantly differed between patients operated on and those who did not require surgery ( $80 \%$ vs $45.2 \%$; $P=0.02$ ). The difference in the balloon-to-annulus ratios between the groups was borderline significant $(P=0.05)$. The remaining parameters listed in TABLE 4 did not significantly differ between the groups.

In patients undergoing surgery, the mean (SD) $\mathrm{PG}_{\max }$ at late follow-up was 32.2 (15.6) $\mathrm{mm} \mathrm{Hg}$ and did not differ from that noted in those who did not require surgery $(P=0.2)$.

Multivariate analysis, by backward logistic regression, revealed that risk factors for the need for surgery included AR of grade higher than 2 at late follow-up $(P<0.001 ; \mathrm{OR}, 1000)$, a $\mathrm{PG}_{\max }$ less than $35 \mathrm{~mm} \mathrm{Hg}$ at late follow-up $(P=0.01$; $\mathrm{OR}, 810)$, and $P_{\mathrm{max}}$ greater than $35 \mathrm{~mm} \mathrm{Hg}$ directly after the procedure $(P=0.007 ; \mathrm{OR}, 127)$. No significance was shown for age at BAV and the balloon-to-annulus ratio. 

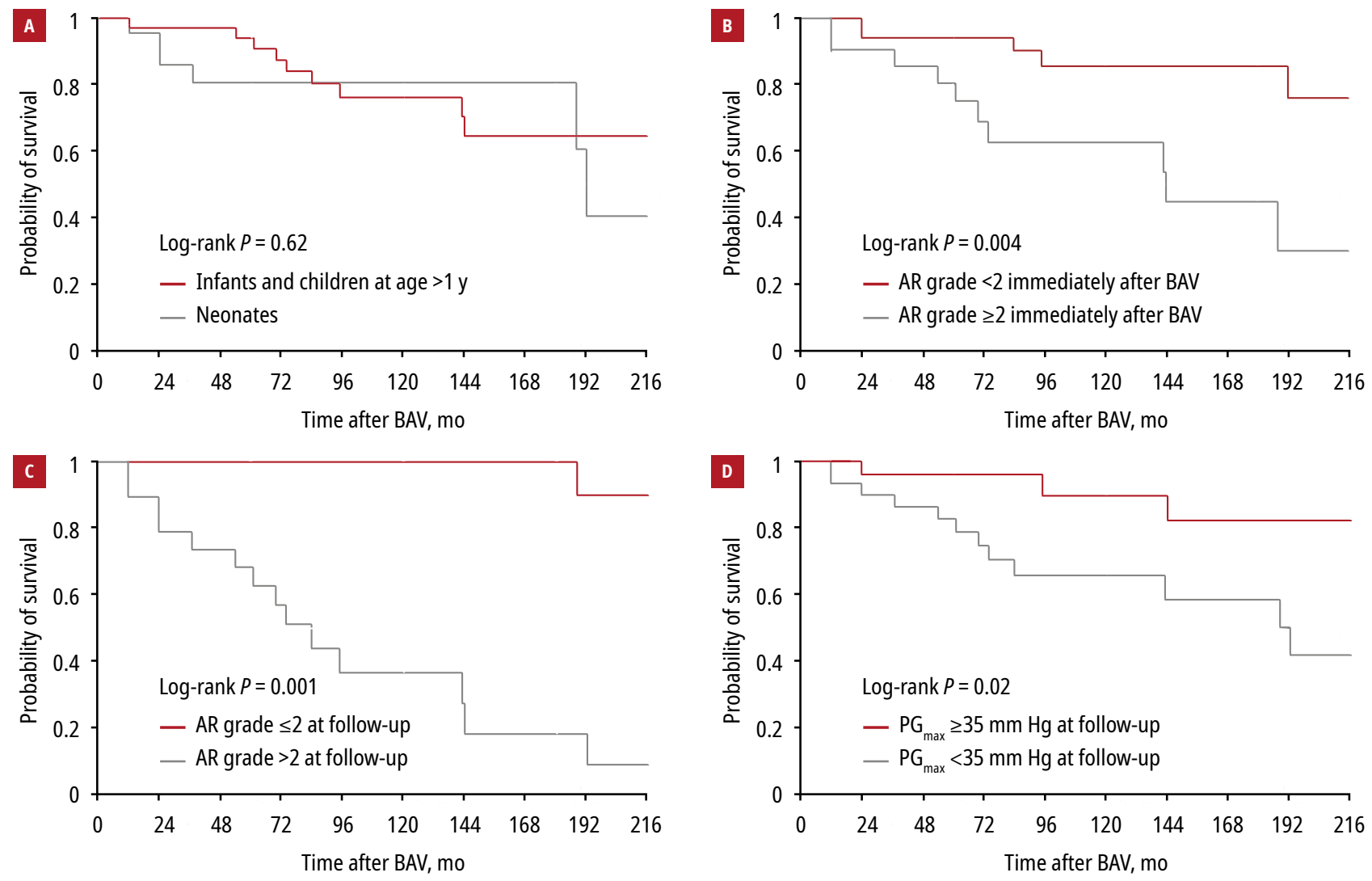

FIGURE 3 Kaplan-Meier curves showing the probability of survival without surgical reintervention (log-rank test) after balloon aortic valvuloplasty (BAV) for particular age groups (A), patients with aortic regurgitation (AR) of grade $\geq 2$ immediately after BAV (B), patients with AR of grade $>2$ at long-term follow-up (C), and patients with $P G_{\max } \geq 35 \mathrm{~mm} \mathrm{Hg}$ at long-term follow-up (D)

TABLE 4 Selected factors noted in the operated and nonoperated groups of patients at long-term follow-up after balloon aortic valvuloplasty

\begin{tabular}{|c|c|c|c|c|}
\hline \multicolumn{2}{|l|}{ Parameter } & Nonoperated group $(n=42)$ & Operated group $(n=15)$ & $P$ value \\
\hline \multirow[t]{3}{*}{ Age group, \% } & Newborns & 59.5 & 60 & \multirow[t]{3}{*}{0.69} \\
\hline & Infants & 26.2 & 33.3 & \\
\hline & Children at age $>1 \mathrm{y}$ & 14.3 & 6.7 & \\
\hline \multicolumn{2}{|c|}{$\mathrm{PG}_{\max }$ before $\mathrm{BAV}, \mathrm{mm} \mathrm{Hg}$, mean (SD); range } & $76.26(18.36) ; 25-120$ & $68.7(16.45) ; 42-100$ & 0.16 \\
\hline \multicolumn{2}{|c|}{$\mathrm{PG}_{\max }$ immediately after $\mathrm{BAV}, \mathrm{mm} \mathrm{Hg}$, mean (SD); range } & $28.66(9.05) ; 13-50$ & $30.4(10.1) ; 20-52$ & 0.62 \\
\hline \multicolumn{2}{|c|}{$\mathrm{PG}_{\max }$ at long-term follow-up, $\mathrm{mm} \mathrm{Hg}$, mean (SD); range } & $34.8(14.4) ; 5-76$ & $32.2(15.6) ; 20-85$ & 0.2 \\
\hline \multirow[t]{2}{*}{$P G_{\max }$ at long term follow-up, $\%$} & $<35 \mathrm{~mm} \mathrm{Hg}$ & 45.2 & 80 & \multirow[t]{2}{*}{0.02} \\
\hline & $\geq 35 \mathrm{~mm} \mathrm{Hg}$ & 54.8 & 20 & \\
\hline \multirow[t]{2}{*}{ AR at long term follow-up, \% } & Grade $>2$ & 11.9 & 93.3 & \multirow[t]{2}{*}{$<0.001$} \\
\hline & Grade $\leq 2$ & 88.1 & 6.7 & \\
\hline \multirow[t]{2}{*}{ AR immediately after BAV, \% } & Grade $>2$ & 30.5 & 66.7 & \multirow[t]{2}{*}{0.005} \\
\hline & Grade $\leq 2$ & 69.5 & 33.3 & \\
\hline \multicolumn{2}{|c|}{$\begin{array}{l}\text { Reduction in the pre-BAV PG }{ }_{\max } \text { value immediately after } B A V, \% \text {, mean } \\
\text { (SD); range }\end{array}$} & $60.16(14.67) ; 20-81.2$ & $53.7(17.8) ; 0-70$ & 0.15 \\
\hline \multicolumn{2}{|c|}{ LVIDd z score at long-term follow-up, median (range) } & $1.95(-0.8$ to 6$)$ & $2.68(-2.18$ to 8.34$)$ & 0.75 \\
\hline \multicolumn{2}{|c|}{ Aortic annulus z score at BAV, median (range) } & $-0.13(-1.97$ to 2.75$)$ & $0.15(-1.31$ to 2.32$)$ & 0.41 \\
\hline \multicolumn{2}{|c|}{ LVIDd $z$ score at BAV, median (range) } & $0.25(-2.26$ to 6.67$)$ & $1.29(-0.78$ to 6.32$)$ & 0.07 \\
\hline \multicolumn{2}{|l|}{ LVEF at BAV, \%, mean (SD); range } & $68.45(13.05) ; 25-90$ & $64.2(13.71) ; 40-86$ & 0.28 \\
\hline \multicolumn{2}{|l|}{$\mathrm{B} / \mathrm{A}$ ratio, mean (SD); range } & $0.92(0.06) ;(0.66-1)$ & $0.96(0.05) ;(0.88-1.01)$ & 0.05 \\
\hline
\end{tabular}


DISCUSSION While the immediate results of percutaneous treatment for AS are well documented in numerous studies, ${ }^{4-7}$ only a few reports provide the analysis of the long-term outcomes. 2,5,9,10 Moreover, fetal aortic balloon valvuloplasty for congenital AS may preserve the intrauterine progression into hypoplastic left heart syndrome. ${ }^{8}$ We presented long-term results of treatment for AS in children and analyzed factors affecting these results in a group of 68 patients. Our study, in line with the findings achieved by other authors, confirmed good effectiveness of BAV in reducing PG across the aortic valve directly after the procedure in all age groups. ${ }^{4,5,10-16}$ The severity of AR assessed directly after the procedure was mostly moderate in $98.5 \%$ of patients and severe only in 1 patient. The published studies reported severe AR directly after the procedure at rates ranging from $0 \%$ to $40 \%$, depending on the grading scale (a 3- or 4-point scale), assessment method (angiographic or echocardiographic), definition of severe $A R$ (grade $\geq 2$ or grade $\geq 3$ ), and timing of the procedures. $2,10,12,17-20$

A total of $22 \%$ of the study patients treated with percutaneous BAV developed procedure-related complications. This rate is similar to the rates reported by other authors. ${ }^{5,10,12}$ Most complications (60\%) involved the arteries used during the procedure. An overwhelming majority (71.4\%) of the complications occurred in the newborns. Other authors also reported much higher complication rates in the youngest patients, mainly newborns. , $10^{2}$

During the echocardiographic examination, PG at the last follow-up visit was higher than just after BAV, but it appeared to be significant only in newborns. An increase in the LV-Ao systolic PG after BAV was reported. 6,12,21-23

Other studies emphasized the high incidence and progression of aortic valve dysfunction at late follow-up after BAV. ${ }^{2,3,5,6,24,25}$ We found a significant difference in the proportion of patients with severe AR between the late follow-up time point and the time point directly after the procedure (33.4\% vs $1.5 \%)$. This confirms the progressive nature of postprocedural AR, because the study demonstrated that the proportion of patients with severe AR increased over the long-term follow-up period after the percutaneous procedure. Based on the Kaplan-Meier survival curves, patients are at the highest risk of AR progression within the first 5 years after the procedure.

Balmer et al, ${ }^{6}$ evaluating patients during a follow-up longer than 2 years after BAV, demonstrated a significant increase in the number of patients with moderate-to-severe AR: from $25 \%$ to $50 \%$ in those who underwent the procedure at the age below 3 months, and from $10 \%$ to $39 \%$ in those treated at the age of over 3 months. They also found that the age at BAV did not affect the progression of AR during follow-up after the procedure.

Progression of AR was also reported by McElhinney et al, ${ }^{7}$ who found moderate-to-severe AR in $35 \%$ of the patients 5 years after BAV.

Our study showed that AR of at least grade 2, occurring directly after the procedure, is the strongest factor contributing to the development of severe $A R$ at late follow-up after $\mathrm{BAV}$. The risk factors also include a reduction in LV-Ao PG to less than $35 \mathrm{~mm} \mathrm{Hg}$ on echocardiography directly after the procedure. We also showed the development of severe AR to be related to the balloon size used during the procedure: a larger balloon-to-annulus ratio (but not exceeding 1:1) was observed in the subgroup of patients who had developed severe AR. A larger balloon used during the procedure-while helping to reduce PG more effectively-also contributed to the development of more severe regurgitation directly after the procedure. This led to an increased risk of severe AR at late follow-up.

The results of studies on this issue are inconclusive. Tomita et $\mathrm{al}^{26}$ showed a higher rate of AR progression during the long-term follow-up in patients in whom an adequate $P G$ reduction had been achieved ( $41 \%$ of the patients) than in those with an inadequate PG reduction (25\% of the patients). Porras et $\mathrm{al}^{27}$ correlated immediate results after BAV and long-term outcomes. They concluded that an attempt to achieve a lower gradient $(\leq 35 \mathrm{~mm} \mathrm{Hg}$ ) does not necessarily result in greater AR. This divergence from our observations may be related to the applied methodology of standardized clinical assessment of the BAV procedure, the significance of which was emphasized by the authors.

The progressive dysfunction of the aortic valve after BAV is invariably associated with the potential need for cardiac surgery. The Ross or Ross-Konno procedures were performed in the study patients who required aortic valve replacement. The Ross or Ross-Konno procedures are considered the treatment of choice in young patients owing to valve growth and no need for anticoagulation. Other surgical options for those patients include mechanical or bioprosthetic aortic valve replacement and homograft implantation.

In our study, surgical treatment for AR was not required in $90 \%, 77 \%$, and $59.5 \%$ of the study patients after 5,10 , and 18 years following BAV, respectively. Maskatia et $\mathrm{al}^{3}$ showed that $70 \%$ and $61 \%$ of patients did not require cardiac surgery 10 and 15 years after BAV. Aortic valve surgery was not needed in $79 \%$ and $55 \%$ of patients at 10 and 20 years after BAV, respectively, in a study by Brown et $\mathrm{al}^{24}$ and in $72 \%$ and $66 \%$ of patients, respectively, in a study by Soulatges et al. ${ }^{28}$ 
It is justified to analyze AR and the residual LV-Ao PG at late follow-up in the context of AR and $P G$ measured directly after the procedure. It is therefore relevant to identify risk factors, particularly those modifiable by the operator, which affect the function of the valve in a long-term perspective. Given the difficulty in achieving an optimal outcome, namely a significant reduction of the gradient together with avoiding $\mathrm{AR}$, it needs to be determined what management is more beneficial: leaving the patient with a higher residual gradient or with greater regurgitation. In practical terms, the dilemma is whether to attempt a more aggressive reduction of the gradient at the expense of greater regurgitation or to leave a greater residual gradient.

Our analysis demonstrated that severe AR and a residual PG less than $35 \mathrm{~mm} \mathrm{Hg}$ at late follow-up were stronger risk factors for aortic valve surgery than moderate AR and a PG greater than $35 \mathrm{~mm} \mathrm{Hg}$.

Our results indicate that by avoiding severe $A R$, even at the expense of leaving a residual PG greater than $35 \mathrm{~mm} \mathrm{Hg}$, the patient may benefit most in terms of delaying the surgical intervention. The long-term objective of percutaneous treatment for AS is to delay the need for cardiac surgery for as long as possible. In view of this and given the results of our study, it may be concluded that the aggressive reduction of the LV-Ao PG should not be pursued.

Conclusions Percutaneous BAV is an effective treatment method for AS in children of all age groups, which delays the need for surgical treatment. Aortic regurgitation is a consequence of $\mathrm{BAV}$, which shows progression at late follow-up. A greater reduction in $P G_{\text {max }}$ is a risk factor for at least moderate AR directly after BAV, which results in the progression of $A R$ at late follow-up and the need to perform cardiac surgery sooner.

\section{ARTICLE INFORMATION}

\section{CONFLICT OF INTEREST None declared.}

OPEN ACCESS This is an Open Access article distributed under the terms of the Creative Commons Attribution-Non Commercial-No Derivatives $4.0 \mathrm{In}$ ternational License (CC BY-NC-ND 4.0), allowing third parties to download articles and share them with others, provided the original work is properly cited, not changed in any way, distributed under the same license, and used for noncommercial purposes only. For commercial use, please contact the journal office at kardiologiapolska@ptkardio.pl.

HOW TO CITE Godlewski K, Werner B. Long-term results of percutaneous balloon aortic valvuloplasty in children with aortic stenosis: a single-center experience. Kardiol Pol. 2020; 78: 559-566. doi:10.33963/KP.15245

\section{REFERENCES}

1 Schneider DJ, Moore JW. Aortic stenosis. In: Allen HD, Driscoll DJ, Shaddy RE, Feltes TF, eds. Moss and Adams' Heart Disease in Infants, Children, and Adolescents: Including the Fetus and Young Adults. 7th ed. Lippincott Williams \& Wilkins. 2008: 968-984.

2 Ewert $P$, Bertram H, Breuer J, et al. Balloon valvuloplasty in the treatment of congenital aortic valve stenosis - a retrospective multicenter survey of more than 1000 patients. Int J Cardiol. 2011; 149: 182-185.

3 Maskatia SA, Ing FF, Justino $\mathrm{H}$, et al. Twenty-five year experience with balIoon aortic valvuloplasty for congenital aortic stenosis. Am J Cardiol. 2011: 108: 1024-1028.
4 Egito EST, Moore P, O'Sullivan J, et al. Transvascular balloon dilatation for neonatal critical aortic stenosis. Early and midterm results. J Am Coll Cardiol. 1997; 29: 442-447.

5 McCrindle BW. Independent predictors of immediate results of percutaneous balloon aortic valvotomy in childhood. Valvuloplasty and Angioplasty of Congenital Anomalies (VACA) Registry Investigators: Am J Cardiol. 1996; 77: 286-293.

6 Balmer C, Beghetti M, Fasnacht M, et al. Balloon aortic valvoplasty in paediatric patients: progressive aortic regurgitation is common. Heart. 2004; 90: 77-81.

7 McElhinney DB, Lock JE, Keane JF, et al. Left heart growth, function, and reintervention after balloon aortic valvuloplasty for neonatal aortic stenosis. Circulation. 2005; 111: 451-458.

8 HaponiukJ, Chojnicki M, Paczkowski K, et al. Fetal and neonatal percutaneous aortic balloon valvuloplasty in critical aortic stenosis followed by complex RossRastan-Konno reconstruction. Kardiol Pol. 2019; 77: 1087-1088.

9 Sullivan PM, Rubio AE, Johnston TA, et al. Long-term outcomes and re-interventions fallowing balloon aortic valvuloplasty in pediatric patients with congenital aortic stenosis: a single-center study. Catheter Cardiovasc Interv. 2017; 89: 288-296.

10 Torres A, Vincent JA, Everett A, et al. Balloon valvuloplsty for congerintal aortic stenosis: multi-center safety and efficacy outcome assessment. Catheter Cardiovasc Interv. 2015; 86: 808-820.

11 Lofland GK, McCrindle BW, Williams WG, et al. Critical aortic stenosis in the neonate: a multi-institutional study of management, outcomes, and risk factors. J Thorac Cardiovasc Surg. 2001; 121: 10-27.

12 Reich 0, Tax P, Marek J, et al. Long term results of percutaneous balloon valvoplasty of congenital aortic stenosis: independent predictors of outcome. Heart. 2004; 90: 70-76.

13 Crespo D, Miro J, Vobecky SJ, et al. Experience in a single centre with percutaneous aortic valvoplasty in children, including those with associated cardiovascular lesions. Cardiol Young. 2009; 19: 372-382.

14 Rocchini AP, Beekman RH, Ben Shachar G, et al. Balloon aortic valvuloplasty: results of the Valvuloplasty and Angioplasty of Congenital Anomalies Registry. Am J Cardiol. 1990; 65: 784-789.

15 Petit CJ, Maskatia SA, Justino H, et al. Repeat balloon aortic valvuloplasty effectively delays surgical intervention in children with recurrent aortic stenosis. Catheter Cardiovasc Interv. 2013; 82: 549-555.

16 Eicken A, Georgiev S, Halling G, et al. Neonatal balloon aortic valvuloplasty predictive value of current risk score algorithms for treatment strategies. Catheter Cardiovasc Interv. 2010; 76: 404-410.

17 Maskatia SA, Justino H, Ing FF, et al. Aortic valve morphology is associated with outcomes following balloon valvuloplasty for congenital aortic stenosis. Cath Cardiovasc Intervet. 2013; 81: 90-95.

18 Baram S, McCrindle BW, Han RK, et al. Outcomes of uncomplicated aortic valve stenosis presenting in infants. Am Heart J. 2003; 145: 1063-1070.

19 Jindal RC, Saxena A, Kothari SS, et al. Congenital severe aortic stenosis with congestive heart failure in late childhood and adolescence: effect on left ventricular function after balloon valvuloplasty. Cathet Cardiovasc Intervent. 2000; 51: 168-172.

20 Petit CJ, Gao K, Goldstein BH, et al. Relation of aortic valve morphologic characteristics to aortic valve insufficiency and residual stenosis in children with congenital aortic stenosis undergoing balloon valvuloplasty. Am J Cardiol. 2016; 117: 972-979.

21 Petit CJ, Ing FF, Mattamal RJ, et al. Diminished left ventricular function is associated with poor midterm outcomes in neonates after balloon aortic valvuloplasty. Catheter Cardiovasc Interv. 2012, 80: 1190-1199.

22 Alva C, Sanchez A, David F, et al. Percutaneous aortic valvoplasty in congenital aortic valvar stenosis. Cardiol Young. 2002; 12: 328-332.

23 Knirsch W, Berger F, Kretschmar 0, et al. Balloon valvuloplasty of aortic valve stenosis in childhood: early and medium term results. Clin Res Cardiol. 2008; 97: 587-593.

24 Brown DW, Dipilato AE, Chong EC, et al. Aortic valve reinterventions after balloon aortic valvuloplasty for congenital aortic stenosis intermediate and late follow-up. J Am Coll Cardiol. 2010; 56: 1740-1749.

25 Pedra CA, Sidhu R, McCrindle BW, et al. Outcomes after balloon dilation of congenital aortic stenosis in children and adolescents. Cardiol Young. 2004; 14: 315-321.

26 Tomita H, Echigo S, Kimura K, et al. Balloon aortic valvuloplasty in children a multicenter study in Japan. Jpn Circ J. 2001; 65: 599-602.

27 Porras D, Brown D, Rathod R, et al. Acute outcomes after introduction of a standardized clinical assessment and management plan (SCAMP) for balloon aortic valvuloplasty in congenital aortic stenosis. Congenit Heart Dis. 2014; 9: 316-325.

28 Soulatges C, Momeni M, Zarrouk N, et al. Long-term results of balloon valvuloplasty as primary treatment for congenital aortic valve stenosis: a 20-year review. Pediatr Cardiol. 2015; 36: 1145-1152. 